\title{
The prevalence of diabetes mellitus and an assessment of methods of detection among a community of elderly Chinese in Hong Kong
}

\author{
J. Woo ${ }^{1}$, R. Swaminathan ${ }^{2}$, C.Cockram ${ }^{1}$, C.P.Pang ${ }^{2}$, Y.T. Mak ${ }^{2}$, S. Y.Au' ${ }^{1}$ and J.Vallance-Owen ${ }^{1}$ \\ Departments of ${ }^{1}$ Medicine and ${ }^{2}$ Chemical Pathology, Prince of Wales Hospital, Chinese University of Hong Kong, Shatin, NT, Hong Kong
}

\begin{abstract}
Summary. This study provides information on the prevalence of diabetes mellitus in a group of elderly Chinese subjects aged 60 and above living in the community in Hong Kong, and investigates the sensitivity of the urine sugar, random blood glucose, glycosylated haemoglobin, and fructosamine measurements compared to a glucose tolerance test in screening for diabetes mellitus in this population. Four hundred twenty-seven subjects aged 60 and above were studied. The National Diabetes Data Group Criteria were used for the diagnosis of diabetes. Those with a random blood glucose exceeding $12.5 \mathrm{mmol} / \mathrm{l}$ were considered diabetic, and all of these patients had glycosuria together with elevated total glycosylated haemoglobin and fructosamine concentrations. A diagnostic $75 \mathrm{~g}$ oral glucose tolerance test was performed on patients with one or more of the following
\end{abstract}

abnormalities: glycosuria, random plasma blood glucose $7.8 \mathrm{mmol} / 1$ to $12.5 \mathrm{mmol} / \mathrm{l}$, glycosylated haemoglobin $8.5 \%$, and fructosamine $2.20 \mathrm{mmol} / \mathrm{l}$. By these criteria, the prevalence of diabetes in this community was found to be $9.8 \%$. An elevated random glucose greater than $11.1 \mathrm{mmol} / 1$ proved to be the only specific method of screening and glycosuria was found to be at least as good as fructosamine and $\mathrm{HbA}_{1}$. However, $\mathrm{HbA}_{1}$ is more sensitive than random glucose, glycosuria or fructosamine in detecting impaired glucose tolerance. On the basis of this study, a higher reference range for glycosylated haemoglobin for the elderly alone is also suggested $(5.74-9.34 \%)$.

Key words: Glycosylated haemoglobin, fructosamine, diabetes mellitus, elderly, Chinese.
The prevalence of diabetes mellitus and blood glucose concentration in response to an oral glucose challenge has been shown to rise with age [1-3]. This has led to the suggestion by some that the criteria for the diagnosis of diabetes mellitus by blood glucose estimation should be higher in the elderly [4]. Despite continuing controversy regarding the criteria of abnormal carbohydrate tolerance in the elderly, there is no doubt that diabetes increases morbidity and mortality [5-7]. Therefore, screening for diabetes mellitus as part of the primary health care of the elderly may be important and may reveal a cause for previously unrecognised illhealth.

The prevalence of diabetes mellitus among elderly Chinese is not known, and its determination forms the major aim of this study. The oral glucose tolerance test (OGTT) has been accepted as the ultimate standard for the diagnosis of diabetes mellitus; nevertheless, it is impractical in community screening. In the elderly, it is often difficult to obtain a fasting or an accurate 2-h postprandial blood glucose estimation so that in practice only urine analysis and/or a random blood glu- cose estimation may be possible. In addition, for cultural reasons, elderly Chinese are often reluctant to accept repeated venepunctures as required for an OGTT. Recently, newer methods of screening have been suggested [8] using estimation of glycosylated haemoglobin $\left(\mathrm{HbA}_{1}\right)[9,10]$ or fructosamine [11] on a random blood specimen. Although $\mathrm{HbA}_{1}$ has a high predictive value only in long-standing hyperglycaemia in a group of patients of all ages [12], its value in screening has not been studied in the elderly. There is also little information regarding serum fructosamine levels in the elderly for the detection of diabetes mellitus. This study compares the sensitivity of urine sugar, random blood glucose, $\mathrm{HbA}_{1}$ and fructosamine levels in the diagnosis of diabetes mellitus in the elderly, using the OGTT as a standard.

\section{Subjects and methods}

Urine and randomly-timed single blood samples were collected from a cluster sample of 427 Chinese men and women aged 60 and above, mean age $70.6 \pm 4.5$ years, living in sheltered housing, as part of a 
multi-dimensional health assessment of the elderly in the district. There were 177 men and 250 women. The sheltered housing complex consists of flats shared by up to six elderly people, interspersed with flats occupied by other members of the public. The residents of sheltered housing are supervised by members of the Social Welfare Department. The criteria for entry into sheltered housing is that the applicant should be capable of self-care, able to lead a normal active life, but unable to afford their own housing as their income is derived mainly from social welfare. The response rate was $96 \%$, the reason for refusal being fear of blood taking.

Blood specimens for $\mathrm{HbA}_{1}$ and fructosamine estimation were collected in EDTA containers, as fructosamine values have been shown by our group to be indistinguishable from serum values if EDTA is used as preservative, but lower if fluoride oxalate or heparinised containers are used [13].

Plasma glucose was measured with the glucose (Trinder) assay kit on an Encore centrifugal analyzer (Baker, Allentown, Penn, USA). The assay employed the glucose oxidase-peroxidase double enzyme system with 4-aminolenazone as the chromogenic oxygen receptor.

Fructosamine was determined by the reduction of nitro-blue tetrazolium in alkaline solution [14]. This colorimetric assay was automated on a Cobas Bio centrifugal analyser (F Hoffmann-La Roche, Basle, Switzerland) using commercially availabe 1-deoxy-1-morpholino-D-fructose and Roche control sera as primary and secondary calibrants. Plasma total protein and albumin were measured by standard methods. Plasma fructosamine concentration was corrected for change in total protein and albumin concentration according to the formula: corrected fructosamine $=$ Fructosamine $+0.006(70-$ Total Protein) +0.013 (40 - Albumin) [15].

$\mathrm{HbA}_{1}$ in whole blood was measured on agar gel by a Corning 'Glytrai' Electrophoresis Apparatus (Corning, Palo Alto, Calif, USA). Haemolysis was carried out with the use of the Corning haemolysing reagent $(0.1 \%$ saponin) immediately prior to electrophoresis.

The reference ranges for $\mathrm{HbA}_{1}$ and fructosamine obtained in younger subjects were used, as reference ranges specific for the elderly were not available at the beginning of the study $\left(8.5 \%\right.$ for $\mathrm{HbA}_{1}$ and $2.20 \mathrm{mmol} / 1$ for corrected fructosamine).

It has been suggested that in the elderly, the diagnosis of diabetes mellitus is highly probable if the random glucose is greater than $13.3 \mathrm{mmol} / 1$ and probable if it is greater than $11.1 \mathrm{mmol} / 1$ [4]. We used an arbitrary figure of $12.5 \mathrm{mmol} / \mathrm{l}$ as the cut-off point, so that all subjects with a random glucose greater than $12.5 \mathrm{mmol} / 1$ were considered diabetic. All of these subjects also had glycosuria, elevated $\mathrm{HbA}_{1}$ and fructosamine. A 75-g OGTT was performed on all subjects with either one or more than one of the following abnormalities: glycosuria, random glucose between 7.8 and $12.5 \mathrm{mmol} / \mathrm{l}, \mathrm{HbA}_{1}$ greater than $8.5 \%$ and fructosamine greater than $2.20 \mathrm{mmol} / 1$. Prior to the OGTT the subjects were fasted overnight and all morning medications were omitted. As far as was possible it was ensured that the patients ate a carbohydrate-rich diet for 3 days prior to the OGTT. Rice formed the main component of carbohydrate in the diet. All OGTTs were carried out in the morning between $09.00-11.30$ hours, in the metabolic investigation unit of a general hospital, at a constant ambient temperature of $25^{\circ} \mathrm{C}$. The National Diabetes Data Group criteria for diagnosis of diabetes mellitus and impaired glucose tolerance were used [16]. A diagnosis of diabetes mellitus was made if the plasma glucose at 1 and $2 \mathrm{~h}$ after $75 \mathrm{~g}$ oral glucose were both equal to or greater than $11.1 \mathrm{mmol} / 1$, and a diagnosis of impaired glucose tolerance (IGT) was made if the fasting glucose was less than $7.8 \mathrm{mmol} / 1$, the $1 \mathrm{~h}$ glucose $11.1 \mathrm{mmol} / 1$ or greater, and the 2-h glucose between 7.8-11.1 mmol/l.

\section{Statistical analysis}

The probability of significant difference between different percentages in Tables 3 and 4 was calculated by dividing the difference between two values by its standard error.
Table 1. Age distribution of diabetic and non-diabetic subjects

\begin{tabular}{|c|c|c|c|c|c|c|c|}
\hline \multirow[t]{2}{*}{$\begin{array}{l}\text { Age range } \\
\text { (years) }\end{array}$} & \multicolumn{2}{|c|}{$\begin{array}{l}\text { Number of } \\
\text { non-diabetic } \\
\text { subjects }\end{array}$} & \multicolumn{2}{|c|}{$\begin{array}{l}\text { Number of } \\
\text { diabetic } \\
\text { subjects }\end{array}$} & \multicolumn{3}{|c|}{$\begin{array}{l}\text { Prevalence of } \\
\text { diabetes mellitus } \\
(\%)\end{array}$} \\
\hline & $\mathbf{M}$ & $\mathrm{F}$ & M & $\mathrm{F}$ & $\mathbf{M}$ & $\mathbf{F}$ & Total \\
\hline $60-64$ & 18 & 37 & 2 & 3 & 3.3 & 5.0 & 8.3 \\
\hline $65-69$ & 60 & 88 & 4 & 5 & 2.5 & 3.2 & 5.7 \\
\hline $70-74$ & 63 & 90 & 10 & 12 & 5.7 & 6.9 & 12.6 \\
\hline $75+$ & 11 & 18 & 3 & 3 & 8.6 & 8.6 & 17.1 \\
\hline \multicolumn{8}{|c|}{ (Mean age $70.6 \pm 4.5$ years) } \\
\hline Total & \multicolumn{2}{|c|}{385} & \multicolumn{2}{|c|}{42} & \multicolumn{2}{|c|}{9.8} & \\
\hline
\end{tabular}

Table 2. Body mass index (mean \pm SD) in diabetic and non-diabetic subjects in Hong Kong

\begin{tabular}{lll}
\hline BMI $\left(\mathrm{kg} / \mathrm{m}^{2}\right)$ & $\begin{array}{l}\text { Number of } \\
\text { diabetic subjects } \\
(\%)\end{array}$ & $\begin{array}{l}\text { Number of } \\
\text { non-diabetic subjects } \\
(\%)\end{array}$ \\
\hline 25 & $28(66.7)$ & $306(79.4)$ \\
$\begin{array}{l}25-30 \\
\text { (overweight) }\end{array}$ & $11(26.2)$ & $69(18.0)$ \\
$\begin{array}{l}30 \\
\text { (obese) }\end{array}$ & $3(7.1)$ & $10(2.6)$ \\
\hline $\begin{array}{l}\text { Mean } \\
\text { BMI }\end{array}$ & $24.2 \pm 3.2^{\mathrm{a}}$ & $21.9 \pm 3.8^{\mathrm{a}}$ \\
$\mathrm{kg} / \mathrm{m}^{2} \pm \mathrm{SD}$ & (Range 19.3-31.6) & (Range 13.44-34.90) \\
\hline $\mathrm{a} p<0.001$ (Student's t-test) & \\
\hline
\end{tabular}

${ }^{a} p<0.001$ (Student's t-test)

\section{Results}

Nineteen subjects were diagnosed as having diabetes mellitus based on a random plasma glucose of $12.5 \mathrm{mmol} / 1$ or more (The values ranged from 12.5 to $28.9 \mathrm{mmol} / 1)$. Seventy-three underwent a $75-\mathrm{g}$ oral glucose tolerance test; 23 fulfilled the criteria for diabetes mellitus and 13 the criteria for impaired glucose tolerance (IGT). Thus the total number of diabetic subjects was 42 , giving a prevalence of $9.8 \%$ in this population. The prevalence of diabetes appears to rise with age, reaching $17.1 \%$ in those over 75 (Table 1 ). There is no significant difference in prevalence between males and females. The prevalence of IGT by these criteria was $3 \%$. If the WHO criteria (1985) were applied [17], the number of diabetic subjects remained the same, but the number with IGT increased to $20(4.7 \%)$. The remaining 335 subjects, all of whom had a random plasma glucose of $<7.8 \mathrm{mmol} / \mathrm{l}$, no glycosuria and $\mathrm{HbA}_{1}$, and fructosamine concentration within the normal range were classified as normal.

Thirty-three out of $42(76 \%)$ were previously unrecognised cases, and $9 / 42(21.4 \%)$ gave a previous history of diabetes. However, of these nine patients, six had defaulted follow up and the remaining three were all poorly controlled with $\mathrm{HbA}_{1}$ greater than $11 \%$.

Table 2 shows the mean body mass index (BMI \pm SD) of the diabetic and non-diabetic subjects in this 
Table 3. Comparison of the sensitivities of urine sugar, random glucose, $\mathrm{HbA}_{1}$ and fructosamine in detecting diabetes mellitus and impaired glucose tolerance

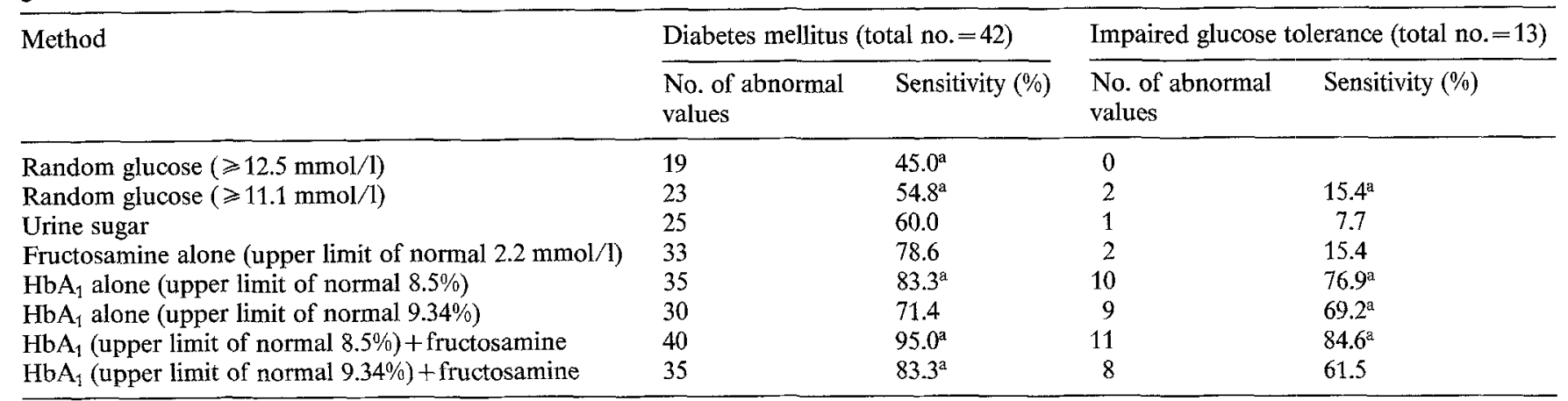

a $p<0.05$

Table 4. Number of subjects with normal OGTT among those with abnormal screening tests

\begin{tabular}{|c|c|c|c|}
\hline Tests & $\begin{array}{l}\text { Total no. with } \\
\text { abnormal values }\end{array}$ & $\begin{array}{l}\text { Number with } \\
\text { normal OGTT }\end{array}$ & $\%$ \\
\hline Urine sugar & 30 & 2 & $6.7^{\mathrm{a}}$ \\
\hline $\begin{array}{l}\text { Random glucose } \\
\geqslant 12.5 \mathrm{mmol} / 1\end{array}$ & 19 & 0 & 0 \\
\hline $\begin{array}{l}\text { Random glucose } \\
\geqslant 11.1 \mathrm{mmol} / 1\end{array}$ & 24 & 0 & 0 \\
\hline $\begin{array}{l}\mathrm{HbA}_{1} \text { alone (upper limit of } \\
\text { normal } 8.5 \% \text { ) }\end{array}$ & 70 & 26 & $37.1^{\mathrm{a}}$ \\
\hline $\begin{array}{l}\mathrm{HbA}_{1} \text { alone (upper limit of } \\
\text { normal } 9.34 \% \text { ) }\end{array}$ & 54 & 11 & 20.4 \\
\hline $\begin{array}{l}\text { Fructosamine alone (upper } \\
\text { limit of normal } 2.2 \mathrm{mmol} \text { ) }\end{array}$ & 49 & 7 & 14.3 \\
\hline $\begin{array}{l}\mathrm{HbA}_{1} \text { (upper limit of } \\
\text { normal } 8.5 \% \text { ) and/or } \\
\text { fructosamine }\end{array}$ & 89 & 37 & $41.6^{\mathrm{a}}$ \\
\hline $\begin{array}{l}\mathrm{HbA}_{1} \text { (upper limit of } \\
\text { normal } 9.34 \% \text { ) and/or } \\
\text { fructosamine }\end{array}$ & 72 & 22 & $30.6^{\mathrm{a}}$ \\
\hline
\end{tabular}

study. The mean BMI in the diabetic group is higher $(p<0.001)$ and there is a higher percentage of overweight (BMI between 25 and $30 \mathrm{~kg} / \mathrm{m}^{2}$ ) and obese (BMI greater than $30 \mathrm{~kg} / \mathrm{m}^{2}$ ) subjects in the diabetic compared to the non-diabetic group.

The sensitivities of the four screening methods in detecting abnormal glucose tolerance among those who underwent this test were calculated by dividing the number of abnormal values among the diabetic subjects by the total number of diabetic subjects (Table 3). $\mathrm{HbA}_{1}$ combined with fructosamine is more sensitive than a random glucose $\geq 12.5 \mathrm{mmol} / 1$ or $\geq$ $11.1 \mathrm{mmol} / 1(p<0.05)$, but not significantly more sensitive than glycosuria. The use of successively lower random glucose levels did not alter the sensitivities significantly, so that only 24 of the 42 diabetic subjects had a random glucose $\geq 10.0 \mathrm{mmol} / \mathrm{l}$. However, $\mathrm{HbA}_{1}$, is more sensitive than random glucose, glycosuria, and fructosamine in detecting impaired glucose tolerance $(p<0.05)$ even though their sensitivities are comparable in detecting diabetes mellitus.

Since the oral glucose tolerance test was used as the absolute criteria for diagnosing diabetes mellitus, but was not carried out on all subjects, we could not calculate the specificity and predictive value of these methods. However, the number of subjects with a normal OGTT despite one or more abnormal screening tests could be given (Table 4). It can be seen that although urine analysis and random plasma glucose measurements gave a low sensitivity, the number of subjects with a normal OGTT, but glycosuria or elevated random plasma glucose, was also low. Although abnormal $\mathrm{HbA}_{1}$ + fructosamine values appeared most sensitive, they also gave the highest number of "false positives" in subjects with a normal OGTT $(p<0.05)$. In particular, there were two subjects with a fructosamine level of 4.36 and $3.57 \mathrm{mmol} / 1$ even after repeat analysis, for which no explanation could be found.

New reference ranges (as mean $\pm 2 \mathrm{SD}$ or $2.5-97.5 \%$ ) for the elderly were then calculated after excluding the subjects with diabetes and IGT, and were $5.74-9.34 \%$ for $\mathrm{HbA}_{1}, 1.64-2.29 \mathrm{mmol} / 1$ for fructosamine and $1.57-2.20 \mathrm{mmol} / \mathrm{l}$ for corrected fructosamine. If these reference ranges are used, then there will be fewer false positives, but the sensitivity falls (Table 4).

The mean fasting glucose level in diabetic subjects was significantly different to that in normal subjects: $6.73 \pm 2.62$ and $4.84 \pm 0.71 \mathrm{mmol} / 1$; mean difference 1.89 (95\% CI 0.98 to 2.81$), p<0.001$. Similarly a significant difference was observed between the IGT and the normal group: $5.41 \pm 1.15$ and $4.84 \pm 0.71 \mathrm{mmol} / \mathrm{l}$; mean difference 0.57 ( $95 \% \mathrm{CI}-0.02$ to 1.11 ), $p<0.05$. No significant difference in the fasting blood glucose level was observed between those with diabetes mellitus and IGT. Significant correlations between fasting and 1-h values, fasting and $2-\mathrm{h}$ values, $1-$ and $2-\mathrm{h}$ values, were seen: $r=0.698, p<0.001 ; r=0.675, p<$ $0.001 ; r=0.793, p<0.001$ respectively.

However despite these findings, the fasting plasma 
glucose is not diagnostic of diabetes in this group of subjects who underwent OGT, if the standard criteria of $7.8 \mathrm{mmol} / \mathrm{l}$ (NDDG or WHO) is used.

\section{Discussion}

When assessing glucose tolerance in any population, but particularly the elderly, it is essential to ensure that the subjects have an adequate carbohydrate intake and activity level. Our sample can be considered representative of the elderly population of Hong Kong in this respect. Thus in another cohort study of 1000 elderly subjects living with relatives or friends, their dietary intake was found to be similar (carbohydrates constituting about $65 \%$ of energy intake) (SC Ho et al; unpublished data); and the mean BMI was $22.7 \pm 4.2 \mathrm{~m} / \mathrm{kg}^{2}$ (60-70 years) and $21.5 \pm 5.3 \mathrm{~m} / \mathrm{kg}^{2} \quad$ (70-80 years), (M. Arumanayagam et al.; unpublished data). Their socioeconomic background can also be considered representative of at least half of the elderly population in Hong Kong, as 96\% belonged or had belonged to occupational group 7 (Hong Kong Census) - production and related workers, labourers, drivers, and $50 \%$ of the working population belonged to this group [18].

The prevalence of diabetes mellitus is lower in South East Asia (1-4\%) [19] compared to Europe and the USA $(5-10 \%)[17]$. The prevalence in Hong Kong Chinese is $3 \%$ in those over 40 years of age [19].

Our finding of an overall diabetes prevalence of $9.8 \%$ in Hong Kong Chinese over 60 , increasing to $17.1 \%$ in those over 75 therefore conforms to the current well recorded general experience that the prevalence rises with age [20]. Prevalence figures for Caucasians vary, depending partly upon criteria and conditions used, but figures of up to $50 \%$ have been reported $[2,21]$ (e.g. in Finland 36-38\% [21]. Lower prevalence figures are also reported including $8 \%$ for known diabetes in American subjects aged over 64 years [22, 23], $17 \%$ in White Americans and $25 \%$ in Black Americans aged 65-74 [24] and 10\% for Danish subjects aged 70 [7]. Thus the prevalence in Hong Kong Chinese is comparable with the lower estimates of prevalence in nonChinese populations.

Many elderly diabetic subjects remain undiagnosed but would meet the updated NDDG criteria for diabetes. It is estimated that 2 million Americans aged 65 or over have undiagnosed diabetes, compared with a similar number in whom the diagnosis is established [25]. In our study 33 of 42 diabetic subjects were not previously diagnosed. Although the natural history of the disease in the elderly remains poorly documented, evidence does exist suggesting that diabetes developing in old age is associated with increased morbidity and mortality from cardiovascular causes. Agner et al. [7] have shown, for example, that diabetic subjects detected by screening at age 70 show excess mortality compared with non-diabetic subjects in the ensuing de- cade. Thus, with such high prevalence rates, screening for diabetes may be a worthwhile measure.

Obesity has been shown to be associated with the increasing prevalence of diabetes mellitus among the elderly [26]. In our study, we also found a higher percentage of overweight and obese subjects among the diabetic group; and unlike the Finnish study [21], the mean body mass index among diabetic subjects is higher than that for non-diabetic subjects. However, the body mass index in our elderly diabetic subjects is similar to that in Finland, where the prevalence is over 3 -fold higher. This suggests that risk factors other than an increased body mass index explain the different prevalence in these two populations.

At present, the oral glucose tolerance test is accepted as a standard in the diagnosis of diabetes mellitus. However, many elderly people dislike repeated venepunctures, and the OGTT is impracticable for routine screening of large populations. The development of estimation of nonenzymatic glycosylation of proteins as an assessment of hyperglycaemia $\left(\mathrm{HbA}_{1}\right.$, and fructosamine) provides possible alternative methods of screening $[8,11]$. The advantage of $\mathrm{HbA}_{1}$ estimation is that it reflects the average prevailing blood glucose level, and only a single blood specimen is required. However it is more expensive than glucose estimation, and may be affected by factors such as renal failure and haemoglobinopathies. The latter is particularly relevant in our community due to the relatively high prevalence of certain haemoglobinopathies [27]. Although cost-risk-benefit evaluation suggests that $\mathrm{HbA}_{1}$ estimation is inferior to a three sample OGTT [10] and that $\mathrm{HbA}_{1}$ is within the reference range in many patients with newly developed diabetes or other minor abnormalities of glucose tolerance [12] it has proved superior to casual blood glucose determination [28].

By contrast, fructosamine estimation is much cheaper than $\mathrm{HbA}_{1}$ or plasma glucose estimation, and is a fully automated procedure. It is also not affected by uraemia unless associated with a serum albumin of less than $30 \mathrm{~g} / 1$. However, it appears to be even less reliable in the detection of subjects with IGT [11]. Most reports on fructosamine evaluate its use in the monitoring of diabetic control $[29,30]$ and there are few reports of its sensitivity and specificity in screening in the elderly.

To date there are few studies comparing the sensitivities of these screening methods [31]. Our results show that both $\mathrm{HbA}_{1}$ and fructosamine together are superior to random blood glucose in the screening for diabetes in the elderly, but not more sensitive than glycosuria. $\mathrm{HbA}_{1}$ is a more sensitive test for detecting $\mathrm{IgT}$, while fructosamine is no better than random glucose estimation or the presence of glycosuria.

The number of abnormal $\mathrm{HbA}_{1}$ and/or fructosamine values among subjects with a normal OGTT is significantly higher than that for glycosuria. One explanation is that the reference ranges for a population 
consisting of many younger subjects is inappropriate for the elderly, and previous reports have shown that $\mathrm{HbA}_{1 \mathrm{C}}$ rises with age $[4,26]$. If the reference range obtained from our non-diabetic elderly population is used, the number of "false positives" decreases, but the decrease is not statistically significant. Interestingly the normal range of $\mathrm{HbA}_{1}$ remains high even when subjects with abnormal OGTT have been excluded, and therefore cannot be entirely explained by the increasing prevalence of diabetes with age, as assessed by plasma glucose measurement or OGTT.

It is possible, although unlikely, that subjects without glycosuria, with a random glucose $<7.8 \mathrm{mmol} / 1$ and normal $\mathrm{HbA}_{1}$, and fructosamine levels may have an abnormal OGT. This question has not been directly addressed in this study. However, in a separate study in which 124 siblings (aged 30-60) of known diabetic patients have been screened using the same criteria, 3 of the 28 diabetic patients detected by screening OGTT had a normal $\mathrm{HbA}_{1}$ and fructosamine (C.S. Cockram, unpublished observations). Thus if one extrapolates these results to the present study $11 \%$ of the diabetic subjects may have been missed (assuming also that the other screening tests were not positive). In this event, the diabetes prevalence would increase from $9.8 \%$ to a maximum of $10.9 \%$. However a greater number of subjects with IGT ( 8 of $14=57 \%$ ) were found to have normal $\mathrm{HbA}_{1}$ and fructosamine and since these subjects are also more likely to have a random blood glucose $<7.8$ and no glycosuria it is possible that the present study underestimates the true prevalence of IGT by as much as $55 \%$.

In the group of patients in whom OGT was performed, the fasting plasma glucose alone is not a diagnosis of diabetes, using the value of $7.8 \mathrm{mmol} / 1 \mathrm{sug}$ gested by the NDDG or WHO. Thus it does not appear to be superior to a single random plasma glucose measurement. The question arises whether this value is applicable to the local Chinese population. Further studies are in progress to address this issue. Follow-up of these subjects in future will be helpful in determining the useful cut-off value for the various tests. A longer term follow-up, for example over 10 years, may give more information to allow comparison of $\mathrm{OGT}, \mathrm{HbA} \mathrm{A}_{1}$ or fructosamine as predictors of future complications related to diabetes.

\section{References}

1. Stout RW (1984) The management of diabetes mellitus in old age. In: O'Malley $\mathrm{K}$ (ed) Clinical pharmacology and drug treatment in the elderly. Churchill Livingstone, Edinburgh London, pp 165-195

2. Andres R (1971) Ageing and diabetes. Med Clin North Am 55: 835-845

3. Fuller JH, Shipley MJ, Rose G, Jarrett RJ, Keen H (1983) Mortality from coronary heart disease and stroke in relation to degree of glycaemia: the Whitehall study. Br Med J 287: 867-870
4. Jackson RA (1984) Blood sugar and diabetes. In: Hodkinson M (ed) Clinical biochemistry of the elderly. Churchill Livingstone, Edinburgh London, pp 209-236

5. Panzram G, Zabel-Langhennig R (1981) Prognosis of diabetes mellitus in a geographically defined population. Diabetologia 20: $581-591$

6. Riddle MC, Hart J (1982) Hyperglycaemia, recognized and unrecognized, as a risk-factor for stroke and transient ischaemic attacks. Stroke 13: 356-359

7. Agner E, Thorsteinsson B, Eriksen M (1982) Impaired glucose tolerance and diabetes mellitus in elderly subjects. Diabetes Care 5: $600-604$

8. Duncan BB, Heiss G (1984) Nonenzymatic glycosylation of proteins - a new tool for assessment of cumulative hyperglycemia in epidemiologic studies, past and future. Am J Epidemiol 120: 169-189

9. Graf RJ Halter JB, Porte D (1978) Glycosylated hemoglobin in normal subjects and subjects with maturity-onset diabetes. Diabetes 27: 834-839

10. Modan M, Halkin H, Karasik A, Lusky A (1984) Effectivness of glycosylated hemoglobin, fasting plasma glucose, and a single post load plasma glucose level in population screening for glucose intolerance. Am J Epidemiol 119: 431-444

11. Baker JR, O'Connor JP, Metcalf PA, Lawson MR, Johnson RN (1983) Clinical usefulness of estimation of serum fructosamine concentration as a screening test for diabetes mellitus. Br Med J 287: 863-867

12. Albutt EC, Nattrass M, Northam BE (1985) Glucose tolerance test and glycosylated haemoglobin measurement for diagnosis of diabetes mellitus - an assessment of the criteria of the WHO Expert Committee on Diabetes Mellitus 1980. Ann Clin Biochem 22: 67-73

13. MacDonald D, Pang CP, Cockram CS, Swaminathan R (1986) Measurement of fructosamine in the assessment of diabetic control. J Med Assoc Thailand 69 [Suppl 3]: 38

14. Johnson RN, Metcalf PA, Baker JR (1982) Fructosamine: a new approach to the estimation of serum glycosylprotein. An index of diabetic control. Clin Chim Acta 127: 87-95

15. MacDonald D, Pang CP, Cockram CS, Swaminathan R (1987) Fructosamine measurements in serum and plasma. Clin Chim Acta 168: 247-252

16. National Diabetes Data Group (1979) Classification and diagnosis of diabetes mellitus and other categories of glucose intolerance. Diabetes 28: 1039-1057

17. World Health Organization (1985) Diabetes mellitus. WHO Tech Rep Ser 727: 103-108

18. Census and Statistics Dept. Hong Kong Census 1981. Main Report, Vol 1

19. Litonjua AD (1986) Diabetes in Southeast Asia. In: Use of sulphonylureas in the management of NIDDM. Farmitalia Carlo Erba Symposia Series. Excerpta Medica Asia, Hong Kong, pp 1-8

20. Davidson MB (1979) The effect of ageing on carbohydrate metabolism: review of the English literature and a practical approach to the diagnosis of diabetes mellitus in the elderly. Prog Endocrinol Metab 28: 688-705

21. Tuomilehto J, Nissinen A, Kivela SL, Pekkanen J, Kaarsalo E, Wolf E, Aro A, Punsar S, Karvonen MJ (1986) Prevalence of diabetes mellitus in elderly men aged 65 to 84 years in Eastern and Western Finland. Diabetologia 29: 611-615

22. Diabetes data compiled 1977. Washington, DC: US Government Printing Office, 1978. Public Health Service. DHEW Publication No (NIH) 78-1468

23. Drury TF, Harris M, Lipsett LF. Prevalence and management of diabetes. In: Health United States 1981. Washington, DC: US Government Printing Office, 1981: 25-31. Public Health Service. DHSS publication No. (PHS) 82-1232

24. Plan and operation of Second National Health and Nutrition Survey 1976-80. Washington, DC: US Government Printing Office, July 1981. Public Health Service, DHHS Publication No (PHS) 81-1317 
25. Bennett PH (1984) Diabetes in the elderly: diagnosis and epidemiology. Geriatrics 39: 37-41

26. Wilson PWF, Anderson KM, Kannel WB (1986) Epidemiology of diabetes mellitus in the elderly. The Framingham Study. Am J Med 80 [Suppl 5A]: 3-9

27. Todd D, Lai MCS, Braga CA, Soo HN (1969) Alpha thalassaemia in Chinese: cord blood studies. Br J Haematol 16: 551-556

28. Ferrell EF, Hanis CL, Aguilar L, Tulloch B, Garcia C, Schull WJ (1984) Glycosylated hemoglobin determination from capillary blood samples. Am J Epidemiol 119: 159-167

29. Lim YS, Staley MJ (1985) Measurement of plasma fructosamine evaluated for monitoring diabetes. Clin Chem 31: 731-733

30. Baker JR, Johnson RN, Scott DJ (1984) Serum fructosamine concentrations in patients with type II (non-insulin-dependent) dia- betes mellitus during changes in management. $\mathrm{Br}$ Med $\mathrm{J} 288$ : 1484-1486

31. Hadden DR, Kennedy L (1984) Fructosamine (Glycosylated protein) and the diagnosis of diabetes. Diabetic Med 1: 91-92

Received: 16 March 1987

and in revised form: 14 August 1987

Dr. Jean Woo

Department of Medicine

Chinese University of Hong Kong

Prince of Wales Hospital

Shatin, N.T.

Hong Kong 